\title{
Conservative Management of an Iatrogenic Arteriovenous Fistula
}

\author{
Robert J.H. Miller ${ }^{a} \quad$ Jennifer M. MacRae ${ }^{b}$ Stefan Mustata ${ }^{b}$ \\ ${ }^{\mathrm{a} D e p a r t m e n t}$ of Medicine, and ${ }^{\mathrm{b}}$ Division of Nephrology, Department of Medicine, \\ University of Calgary, Calgary, Alta., Canada
}

Key Words

Arteriovenous fistula $\cdot$ Catheter $\cdot$ Catheterization $\cdot$ Complications $\cdot$ Fistula

\begin{abstract}
Background: Arteriovenous fistula is an uncommon complication of central venous catheterization that often requires invasive repair. Case Report: We report the case of an arteriovenous fistula that presented as ongoing pain following removal of a tunneled central venous catheter. The fistula resolved spontaneously following a period of compression and observation. Conclusion: Our study highlights the etiology of this uncommon complication as well as suggesting a role for conservative management.

(C) 2014 S. Karger AG, Basel
\end{abstract}

\section{Introduction}

Arteriovenous fistulae (AVF) are an abnormal connection between an artery and a vein that results in increased flow across the connection. They can occur as a congenital malformation but have also been described following central venous catheter insertion [1]. The first case of iatrogenic AVF was published in 1973 by James and Myers [2]. Since that time, multiple case series have described AVF occurring following internal jugular, subclavian, and femoral approaches to central venous access $[1,3,4]$. Classically, the frequency has previously been reported as less than $0.6 \%$ of central line insertions [4]. The use of ultrasound guidance reduces vascular injuries and presumably should decrease the incidence of this already uncommon complication [5].

AVF typically present with symptoms such as pulsatile neck swelling, systolic murmur, palpable thrill, dilated superficial vessels, systemic embolization, limb edema, or infection [4, 
Fig. 1. a Initial Doppler ultrasound of the right internal jugular vein. The arterial flow enters the anteromedial aspect of the internal jugular vein, along the course of the removed central catheter (arrow). b Repeat Doppler ultrasound of the right internal jugular vein demonstrating resolution of the previously documented arterial flow.
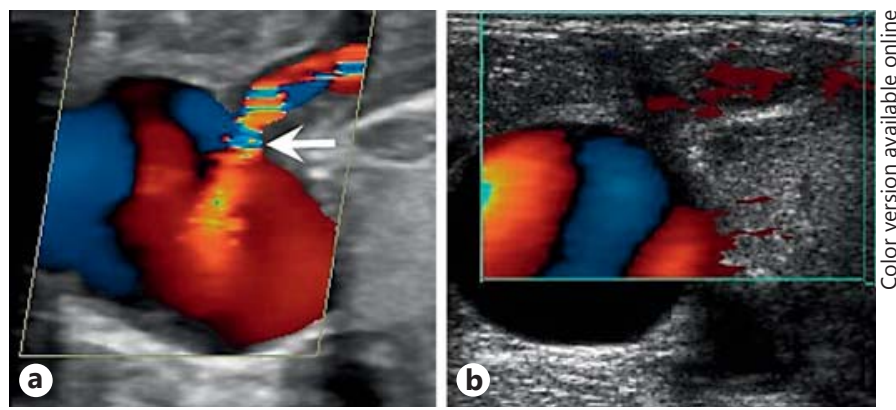

6 , 7]. However, AVF can also present with serious complications including high-output congestive heart failure and systemic embolization $[8,9]$. Given the potential for serious complications, AVF is typically managed with endovascular or surgical repair of the lesion.

We present the case of an iatrogenic AVF that presented only as pain and resolved spontaneously following a trial of compression and observation.

\section{Case History}

A 78-year-old woman was admitted to hospital with acute kidney injury related to urosepsis. Her past medical history included stage 5 chronic kidney disease related to ischemic nephropathy and recurrent nephrolithiasis, atrial fibrillation on oral anticoagulation, severe aortic stenosis, congestive heart failure, hypertension, dyslipidemia, gout, and previous subtotal colectomy for ischemic colitis. She had a progressive decline in kidney function related to sepsis and prerenal acute kidney injury, and subsequently required hemodialysis initiation. She underwent a tunneled cuffed catheter (TCC) insertion 3 days after admission, using ultrasound and fluoroscopic guidance to ensure placement into the right internal jugular vein. The patient's anticoagulation had been held, and her INR was 1.1 at the time of the line insertion; however, she continued on daily acetylsalicylic acid. Her hemodialysis runs were uneventful and there were no issues with the function of her TCC.

One month later, the patient developed fever, tachycardia, and redness along the course of the TCC. She was found to have methicillin-resistant Staphylococcus aureus bacteremia from a presumed catheter-related infection. Her catheter was removed with superficial dissection to release the cuff of the TCC. At that time, the patient's anticoagulation was again held, and her INR was 1.1. Her anticoagulation was resumed without bridging, and the patient was started on a 3-week course of intravenous vancomycin.

The patient had ongoing neck and chest wall pain for several days after removal of the TCC. An MRI of the cervical spine was performed 4 days after TCC removal, which showed no evidence of discitis or osteomyelitis. Seven days after TCC removal, the patient had ongoing pain, with daily narcotic requirements peaking at $45 \mathrm{mg}$ of oral hydromorphone. On exam, the patient had an erythematous, palpable cord over the anterior chest along the course of the removed TCC. There was no thrill, but there was a continuous bruit with systolic accentuation. Ultrasound (fig. 1a) was performed the following day (8 days after TCC removal), which demonstrated a partially thrombosed catheter tract and evidence of an AVF with arterial flow into the lumen of the internal jugular vein that appeared to originate from a superficial muscular arterial branch of the thyrocervical trunk. Given the patient's age and comorbidities, a trial of conservative management was pursued. A pressure bandage was applied, but the patient was unable to tolerate sandbag pressure. Following compression $(12$ 
days after TCC removal), the patient reported less pain; however, a repeat ultrasound showed no significant change in the AVF flow.

After consultation with interventional radiology, the patient was scheduled for selective embolization of the tract. Meanwhile, the patient experienced progressive improvement in her symptoms with a decrease in her narcotic use to $8 \mathrm{mg}$ oral hydromorphone per day. The patient had a repeat ultrasound (fig. 1b) 8 days later ( 20 days from TCC removal) performed by the same technician and the same machine, which identified no evidence of persistent AVF.

\section{Discussion}

AVF is an uncommon complication of central venous catheterization that can have serious complications $[8,9]$. The exact pathophysiology of AVF formation is unclear, but previous proposed mechanisms have focused on damage to adjacent arteries at the time of TCC insertion $[4,7]$. The mechanism in this case may be related to pseudoaneurysm formation at the time of insertion of the TCC from inadvertent arterial puncture. This pseudoaneurysm could have persisted related to the presence of the catheter through the pseudoaneurysm wall. With removal of the catheter, there would be flow from the pseudoaneurysm through the catheter tract to the internal jugular vein. Alternatively, the AVF may have formed as a result of trauma to a superficial arterial branch during catheter cuff dissection. Previous case reports have identified AVF that formed following vascular damage from penetrating trauma [6]. The patient's thin chest wall may have increased the risk of vascular injury during the dissection process.

Previously described predisposing factors for iatrogenic AVF include distal groin punctures, larger needle gauge, arterial hypertension, female gender, periprocedural anticoagulation, and antiplatelet therapy $[3,10]$. Our patient was female, had a history of hypertension, and was taking acetylsalicylic acid throughout her hospitalization. Additionally, our patient had a TCC, which is a large bore catheter. She was anticoagulated for atrial fibrillation, but her anticoagulation was held, with normal coagulation parameters in the periprocedural period. Finally, AVF occurring in the context of central line infection has been previously reported but was also present in our case [11]. Endarteritis predisposes patients to pseudoaneurysm formation suggesting that presence of infection may also increase the risk of AVF formation [12].

Management of AVF has primarily focused on surgical or endovascular repair. In a prospective cohort study of femoral AVF from cardiac catheterization, 38\% closed spontaneously, with the majority closing within the first 3 months [10]. There are no clear guidelines on which AVF require surgical management. Intuitively, larger, more established AVF associated with significant symptoms are more likely to require invasive management. In our case, the fistula was relatively superficial, with a narrow tract. Additionally, on the initial ultrasound in our case there was evidence of thrombus along the AVF tract, suggesting that its natural history was to thrombose without intervention. Patients who have impaired coagulation are less likely to have spontaneous closure suggesting an important role for thrombus formation $[10,13]$. The fact that there was no significant change in the ultrasound appearance following a trial of compression suggests that it probably did not change the natural history of this particular AVF.

While AVF is a relatively rare complication of central venous catheterization, it continues to occur in the era of ultrasound guidance. There may be some features that suggest conservative management is more likely to be successful. 


\section{Disclosure Statement}

The authors have no relevant financial disclosures pertaining to this case report.

\section{References}

1 Gong Y, Xu HX, Lin M, Gu Y: An iatrogenic complication of internal jugular vein catheterization for hemodialysis. Ir J Med Sci 2012;181:135-137.

2 James PM Jr, Myers RT: Central venous pressure monitoring: complications and a new technic. Am Surg 1973; 39:75-81.

-3 Hansbrough JF, Narrod JA, Rutherford R: Arteriovenous fistulas following central venous catheterization. Intens Care Med 1983;9:287-289.

4 Sato O, Tada Y, Sudo K, Ueno A, Nobori M, Idezuki Y: Arteriovenous fistula following central venous catheterization. Arch Surg 1986;121:729-731.

-5 Randolph AG, Cook DJ, Gonzales CA, Pribble CG: Ultrasound guidance for placement of central venous catheters: a meta-analysis of the literature. Crit Care Med 1996;24:2053-2058.

6 Caldarelli C, Biricotti M, Materazzi G, Spinelli C, Spisni R: Acquired carotid-jugular fistula: its changing history and management. ISRN Vasc Med 2013;2013:8.

7 Erkut B, Becit N, Kaygın MA, Velioğlu Y: Iatrogenic arteriovenous fistula between the common carotid artery and internal jugular vein: a case report. Eur J Vasc Endvasc 2005;30:567.

8 Kakkar S, Angelini P, Leachman R, Cooley DA: Successful closure of post-traumatic carotid-jugular arteriovenous fistula complicated by congestive heart failure and cerebrovascular insufficiency. Cardiovasc Dis 1979;6:457-462.

-9 Droll KP, Lossing AG: Carotid-jugular arteriovenous fistula: case report of an iatrogenic complication following internal jugular vein catheterization. J Clin Anesth 2004;16:127-129.

$\checkmark 10$ Kelm M, Perings SM, Jax T, Lauer T, Schoebel FC, Heintzen MP, Perings C, Strauer BE: Incidence and clinical outcome of iatrogenic femoral arteriovenous fistulas: implications for risk stratification and treatment. J Am Coll Cardiol 2002;40:291-297.

11 Siu DY, Wong GK, Ho SS, Yu SC, Lam YH, Poon WS: Iatrogenic carotid-jugular fistula. Hong Kong Med J 2009; 15:313-314.

-12 McCready RA, Siderys H, Pittman JN, Herod GT, Halbrook HG, Fehrenbacher JW, Beckman DJ, Hormuth DA: Septic complications after cardiac catheterization and percutaneous transluminal coronary angioplasty. J Vasc Surg 1991;14:170-174.

13 Kresowik TF, Khoury MD, Miller BV, Winniford MD, Shamma AR, Sharp WJ, Blecha MB, Corson JD: A prospective study of the incidence and natural history of femoral vascular complications after percutaneous transluminal coronary angioplasty. J Vasc Surg 1991;13:328-333. 